\title{
Cuando azota el frío. Globalización y afectividad de Álvaro Vega Sánchez (EUNA, 2017)
}

\section{Cuando azota el frío. [When the cold hits ] Globalization and affectibility by Álvaro Vega Sánchez (EUNA, 2017)}

\section{Cuando azota el frío. [Quando o frio atinge] Globalização e afetividade de Álvaro Vega Sánchez (EUNA, 2017)}

Adriano Corrales-Arias

Escritor, poeta

El profesor, investigador y escritor Álvaro Vega Sánchez nos coloca ante una nueva parcela de la realidad contemporánea al introducir en el análisis de la globalización la dimensión afectiva. Es decir, nos propone una mirada nueva a la conexión entre la producción material y la producción simbólica en el sistema-mundo como una herramienta teórico/ metodológica para re-constituir un nuevo sujeto histórico que pudiera rectificar el rumbo de la globalización.

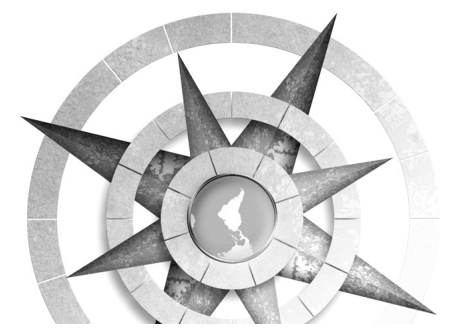

1. Los nuevos movimientos sociales de
la dignidad y contra la exclusión, como
"Los Indignados" en Europa o las "prima-
veras árabes", que luchan por sociedades

1. Los nuevos movimientos sociales de
la dignidad y contra la exclusión, como
"Los Indignados" en Europa o las "prima-
veras árabes", que luchan por sociedades

1. Los nuevos movimientos sociales de
la dignidad y contra la exclusión, como
"Los Indignados" en Europa o las "prima-
veras árabes", que luchan por sociedades

1. Los nuevos movimientos sociales de
la dignidad y contra la exclusión, como
"Los Indignados" en Europa o las "prima-
veras árabes", que luchan por sociedades
Dicho de otro modo, Vega Sánchez nos muestra un camino alternativo hacia una ética de la solidaridad y del bien común para la equidad y la justicia en un nuevo orden social. Esa ética debe concretarse y expresarse en la corporalidad diversa del individuo inserto en el cuerpo sociocultural; es decir, debe considerar los afectos como elementos sine quam nom de la configuración, la pluralidad y dignidad humanas. Dentro de esa perspectiva, y en tres capítulos, el autor considera cuatro ámbitos donde se percibe la construcción de un nuevo orden social más humano y solidario:
Julio-diciembre, 2018143 Vol. 34, N. ${ }^{\circ} 64$ 
más equitativas y justas con métodos de lucha novedosos y democráticos, horizontales, donde la comunicación asertiva y la afectividad asumen un rol preponderante. En este punto nos atrevemos a subrayar a los movimientos estudiantiles y sociales de Nicaragua y Costa Rica, los cuales, salvando las distancias, recientemente han puesto en jaque a los gobiernos de ambos países vanguardizando una revuelta de protesta nacional ante abusos del poder e imposición de medidas fiscales y socieoeconómicas abusivas.

2. Los esfuerzos para cimentar una comunidad global intercultural que potencie y alcance un verdadero entendimiento pluriversal y una sana convivencia planetaria. Se trata de la construcción de una nueva sociedad global que trascienda fronteras creando nuevas identidades $y$ sentidos de pertenencia con respecto al patrimonio cultural de todos los pueblos de la tierra en un dialogo que potencie y respete las diferencias y contribuya a eliminar las desigualdades.

3. La irrupción de una nueva ciudadanía contra la violencia y por el diálogo para lograr que los ciudadanos del mundo tengan, cada vez más, una presencia protagónica en el planteamiento de modelos sociopolíticos alternativos. Ante la dictadura del mercado y sus agentes transnacionales, se propone una mesa de auténtico diálogo democrático que apunte hacia nuevas dimensiones afectivas y lúdicas que pudieran salvaguardar los intereses de las mayorías bajo los criterios de justicia, equidad y solidaridad. Se trata de la mesa del bien común, o del "buen vivir" y del "bien estar".

4. Las iniciativas y propuestas para la defensa de la vida desde una concepción bioecosistémica planetaria. En este apartado el símbolo o metáfora es la casa ("oikos"), no solo como espacio físico sino como medio ambiente donde se protegen y conviven los seres vivos. Es el sitio, el "hogar", donde se crea, recrea y disfruta la vida: la tierra como "casa" de todos. Porque somos parte de una intensa red de relaciones que nos conectan al proceso creativo del universo y, si logramos crear un ambiente holístico o bioecosistémico, lograremos un nuevo pacto con la tierra y la humanidad conducente a una unidad superior de cultura, a una comunidad global afectiva. 
Dentro de esos cuatro ámbitos el factor emotivo/afectivo es central. En esa construcción alternativa, donde las emociones y la expresión de las mismas, cual auténtica poiesis, sean el camino hacia una nueva humanidad, se debe tener en cuenta que la misma será posible solo si se alcanza a través de la creación colectiva en la cual todos los actores tengan participación activa, tanto en la "dramaturgia" como en la puesta en escena. Para ello es imprescindible la construcción de un nuevo paradigma teórico y metodológico.

Es claro que las narrativas decimonónicas ancladas aún en el análisis sociopolítico, tanto en su teoría como en su praxis, deben dar paso a nuevas experiencias cognoscitivas donde la interdisciplinariedad y la transdisciplinariedad sean claves. En esas nuevas experiencias, en ese nuevo paradigma, hay que acopiar, aprovechar y dialogar con los saberes que estuvieron y están invisibilizados por la razón occidental, es decir, los saberes alternativos y nómadas procedentes de las periferias o de los espacios/tiempo coloniales del sistema-mundo capitalista. Es un proceso hacia una suerte de intergnosis, o de una "ecología de saberes", tal y como lo conceptúa el portugués Boaventura de Sousa Santos.
El texto nos enfrenta a tres desafíos actuales, dicho de otra manera, a tres emociones principales, las cuales, incluso, según Dominique Moisi, en una suerte de "geopolítica de las emociones", pueden ubicarse geográficamente: el miedo, la esperanza y la humillación. Estas emociones, para el caso de América latina, por ejemplo, aplican en su amplitud, de tal modo que somos un subcontinente del miedo y de la humillación, pero, a su vez, con mucha esperanza.

Ahora bien, Sánchez Vega no se queda solo en el diagnóstico y en la propuesta, sino que también nos ofrece una pedagogía de las emociones, mejor dicho, una didáctica para el aprendizaje colectivo de la afectividad. Así, la inteligencia emocional puede formarse, puede y debe desarrollarse; en ese sentido el autor nos describe una serie de destrezas que consiguen enseñarse, tales como el autodominio y la compasión. Ello quiere decir que la afectividad se construye socialmente, para ello se debe edificar una ambientación sociocultural solidaria que permita el desarrollo cualitativo del factor corporal/emotivo.

Se trata, en última instancia, de un nuevo humanismo para alcanzar la unidad superior de cultura que permita la aparición de un nuevo sujeto

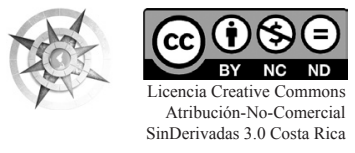


humano. Ello implica cambiar las reglas del sistema y las normas de la conversación: revolucionar y revolucionarnos para que la competitividad acerba del mercado total ceda ante la socioeconomía y la cooperación responsable. Quiere decir que para alcanzar la dignificación de la corporalidad humana integral, o sea, diversa y sensible, debemos reaprender a sentir, a reconocer y a compartir. Planteado de otra manera, reaprender a sembrar para vivir plenamente, perseverar para amar integralmente; generar una auténtica y cotidiana cultura de la esperanza.

Septiembre, 2018 